\title{
Operative findings after percutaneous pulmonary balloon dilatation of the right ventricular outflow tract in tetralogy of Fallot
}

\author{
Sergio A Battistessa, Alfonso Robles, Mark Jackson, Satoru Miyamoto, Robert Arnold, \\ Roxane McKay
}

\begin{abstract}
Since 1983 percutaneous balloon dilatation of the right ventricular outflow tract has been performed as an alternative to surgical palliation in selected cases of tetralogy of Fallot at the Royal Liverpool Children's Hospital. From 31 December 1984 to 31 December 1988, 27 of these patients underwent subsequent surgical correction. Age at operation ranged from 7 to 58 months (median $2 \cdot 7$ years). The mean interval between balloon dilatation and correction was 15.6 months (range 3-39 months). Two patients had a systemic pulmonary shunt operation performed before dilatation and a further five required one afterwards. Overall $20(74 \%)$ patients had some anatomical alteration as the result of balloon dilatation, while in seven $(26 \%)$ there was no discernible change in the right ventricular outflow tract. There was no consistent relation between the ratio of balloon size to pulmonary annulus diameter and the morphological findings.

Balloon dilatation may obviate the need for systemic-pulmonary shunt at the expense of some structural damage, particularly to the posterior cusp. The present data suggest that dilatation does not bring about growth of the annulus to such an extent that transannular patch is no longer needed at intracardiac repair.
\end{abstract}

Since percutaneous pulmonary balloon dilatation was introduced in $1953,{ }^{1}$ it has become the treatment of choice for pulmonary valve stenosis in many centres. As suggested initially by Semb et $a l^{2}$ and Kan et $a l^{3}$ the haemodynamic results compare favourably with those of surgery, especially when dysplastic valves are excluded. Because of this, few patients come to operation and the numerous published series ${ }^{4-6}$ contain little information on the morphological effects of dilatation of the right ventricular outflow tract. $^{578}$

In our hospital, percutaneous pulmonary balloon dilatation has been practised as an alternative to or in combination with surgical palliation in selected patients with tetralogy of Fallot.9 Because most of these patients will eventually undergo operation we were presented with an opportunity to observe the anatomical consequences of dilatation of the right ventricular outflow.
Patients and methods

From 31 December 1984 to 31 December 1988, 27 patients underwent correction of tetralogy of Fallot after previous balloon dilatation of the right ventricular outflow tract. This includes 15 of those reported in the original clinical series. ${ }^{9}$ We reviewed the clinical notes; the operative reports; and, when available, the necropsy specimens.

The median age of the patients at operation was 33 months (range 7-58 months). Twenty one of them had one pulmonary dilatation, four had two procedures, and two patients had three and four balloon dilatations. The mean age at the first dilatation was 10.0 months (range 0.5 30 ); for all dilatations the median age was $14 \cdot 6$ months (range 0.5-56). Balloon sizes ranged from 5 to $15 \mathrm{~mm}$ (mean $13 \mathrm{~mm}$ ). Surgical correction was undertaken 3 to 39 months (mean 15.6 months) after dilatation.

At operation the surgeon classified the pulmonary valve leaflets as follows: (a) intact, when there was no observable effect of dilatation; (b) detached, when the leaflet was separated from its hinge-point for a variable length, starting from one of the commissures; (c) split, when a vertical tear was found, usually in mid-portion of the leaflet dividing it in two segments (in no case was a split identified at a commissure); ( $d$ f fused, when the leaflets were fused to the pulmonary artery wall, probably after initial detachment.

The pulmonary ventriculo-arterial junction (pulmonary annulus) was described as: (a) intact, where there was no observable effect of dilatation; or (b) split, when there was a tear usually originating at the hinge-point of the leaflet and extending a variable distance into the main pulmonary artery and its right branch.

The computerised records of all the other patients (113) who underwent correction of tetralogy of Fallot over the same period (31 December 1984-31 December 1988) and who did not have balloon dilatation were reviewed to determine how many later had systemicpulmonary shunt operations performed at our hospital or elsewhere and how many required a transannular patch at the time of correction.

All patients underwent intracardiac repair of tetralogy of Fallot by standard surgical techniques on conventional cardiopulmonary bypass. In most patients we used accepted criteria for the predicted ratio of postoperative right and left ventricular pressures to decide whether or not a transannular patch was required. The ventricular septal defect usually was closed through the right atrial approach. 
Figure 1 Posterior leaflet of pulmonary valve after percutaneous pulmonary balloon dilatation showing the frequently encountered vertical tears (split leaflet) (arrows). More often, however, this consisted of a single tear from free edge to the hingepoint of the cusp. $R V$, right ventricle; $P A$ pulmonary artery.

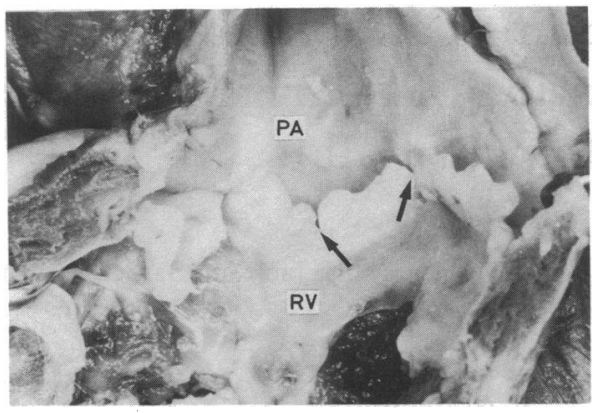

We used simple logistic regression analysis to examine whether the ratio of balloon size to pulmonary artery diameter predicted morphological changes in the pulmonary artery. We analysed the frequency of transannular patch and shunt operations in patients treated by dilatation and those who were not by the $\chi^{2}$ test. We regarded $p$ values of between $0.05-0.1$ as statistically significant. We calculated the $70 \%$ confidence intervals for all percentages.

\section{Results}

Table 1 shows the findings at operation. Figure 1 is an example of a split leaflet. Overall 20 of the patients $(74 \%)(70 \%$ CI $63 \%-83 \%)$ had gross evidence of damage caused by balloon dilatation. Seven patients $(26 \%)(70 \%$ CI $17 \%-37 \%$ ) had an intact outflow. Only five $(19 \%)(70 \%$ CI $11 \%-29 \%)$ had evidence of changes that extended to more than one morphological category. No valve was found to have been split along a commissure and most valves described as "intact" were still obstructive with fused commissures. In five (19\%) $(70 \%$ CI $11 \%-29 \%)$ there was a posterior split of the pulmonary arterial wall (fig 2), starting at the ventriculo-arterial junction and often

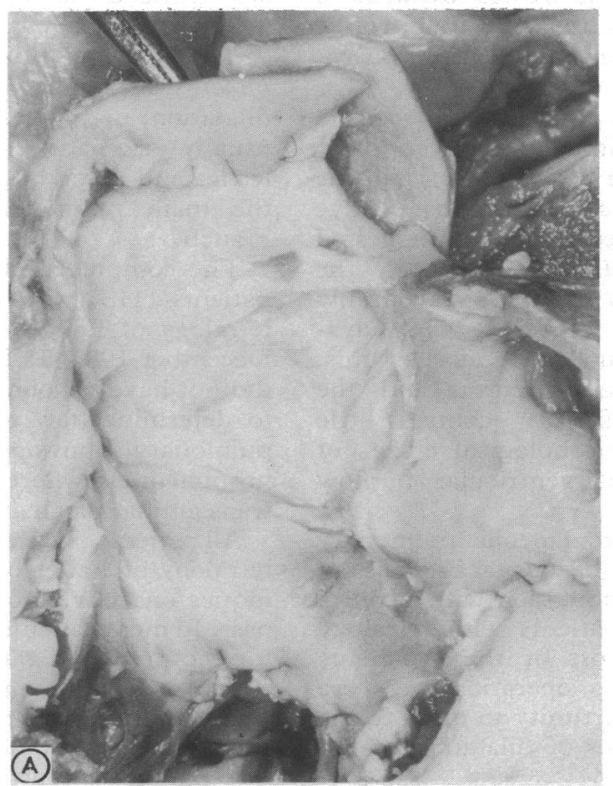

Table 1 Findings at operation

\begin{tabular}{lrll}
\hline Morphology & $n$ & $\%$ & $70 \% C I(\%)$ \\
\hline Leaflets: & 7 & 26 & $17-37$ \\
Intact & 8 & 30 & $20-41$ \\
Detached & 9 & 33 & $23-45$ \\
Split & 8 & 30 & $20-31$ \\
Fused & & & \\
Annulus: & 22 & 81 & $71-89$ \\
$\quad$ Intact & 5 & 19 & $11-29$ \\
Split & &
\end{tabular}

Table 2 Relation between ratio of balloon size to pulmonary artery annulus and operative findings in terms of patient numbers and the results of logistic regression analysis of the stratified results

\begin{tabular}{|c|c|c|c|c|}
\hline \multirow[b]{2}{*}{$\begin{array}{l}\text { Balloon } / P A \\
\text { range (\%) }\end{array}$} & \multicolumn{4}{|l|}{ Operative findings } \\
\hline & $\begin{array}{l}\text { Morphological damage } \\
\text { (n) }\end{array}$ & $\begin{array}{l}\text { Intac } \\
(n)\end{array}$ & & Total \\
\hline $\begin{array}{l}<120 \\
121-140 \\
141-160 \\
161-180 \\
181-200 \\
>201\end{array}$ & $\begin{array}{l}4 \\
2 \\
6 \\
1 \\
4 \\
1\end{array}$ & $\begin{array}{l}3 \\
2 \\
1 \\
1 \\
0 \\
0\end{array}$ & & $\begin{array}{l}7 \\
4 \\
7 \\
2 \\
4 \\
1\end{array}$ \\
\hline Totals & 18 & 7 & & $25^{\star}$ \\
\hline $\begin{array}{l}\text { Constant (SE) } \\
-0.49(0.87)\end{array}$ & $\begin{array}{l}\text { Balloon/PA ratio (SE) } \\
0.58(0.38)\end{array}$ & $\begin{array}{l}t \\
1.52\end{array}$ & $\begin{array}{l}\text { df } \\
23\end{array}$ & $\begin{array}{l}\mathrm{p} \\
<0.2\end{array}$ \\
\hline
\end{tabular}

extending into the right branch. In one of the patients who died, gross and microscopical examination showed extensive disruption of the tissues (fig 3). The endothelial continuity was lost posteriorly at the depressed and uneven area that corresponded with the macroscopic tear, although the adventitia remained intact. Subendocardial fibrosis and elastosis were conspicuous in all sections of the adjacent right ventricular outflow septum in this patient.

Table 2 shows the relation between the ratio of the balloon size to the angiographic diameter of the pulmonary annulus and the frequency of

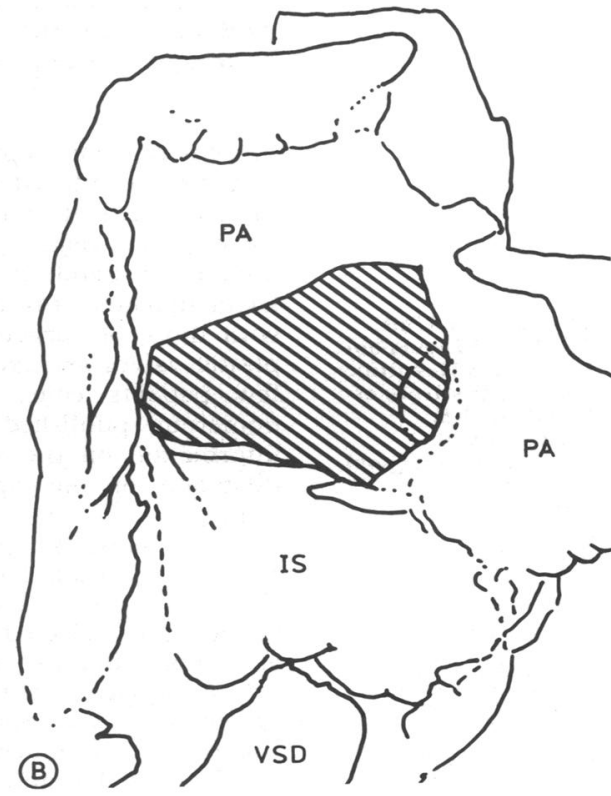

Figure 2 Posterior aspect of main pulmonary trunk opened anteriorly. The pulmonary valve leaflets were excised intraoperatively. The ventricular septal defect patch has been removed. The tear in the arterial wall (shaded area of corresponding diagram) shows the loss of endothelial continuity.

$P A$, pulmonary artery; IS, infundibular septum, $V S D$, ventricular septal defect. 


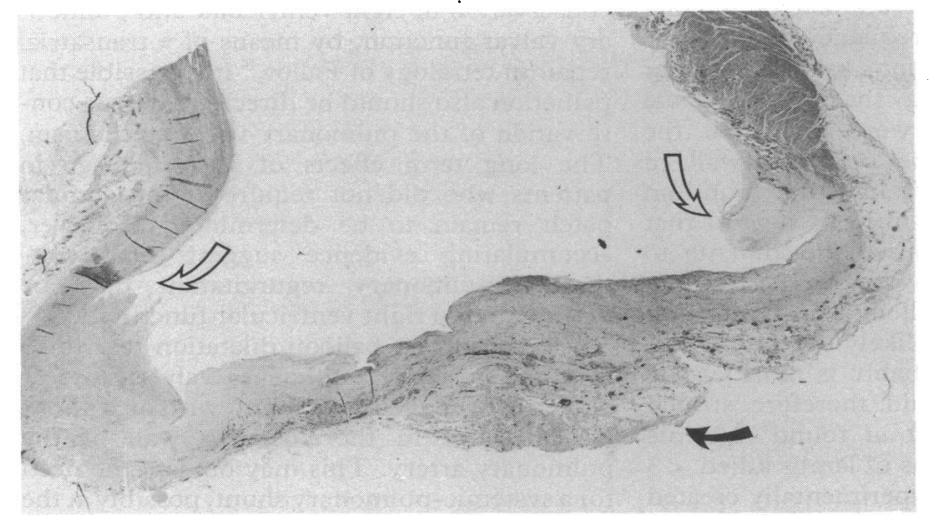

Figure 3 Photomicrograph of a transverse section through the shaded area of the specimen shown in fig 2 . There was a loss of endothelial wall continuity in the central depressed area (between open arrows). There were masses of eosinophilic degenerated tissue in the underlying fibroelastic corion. The adventitia was intact (closed arrow). Haematoxylin and eosin stain, original magnification $\times 3$.

Figure 4 Observed frequency of alterations in the pulmonary valvel ventriculo-arterial junction, according to the ratio of balloon size to angiographic pulmonary annulus diameter. The bars show the $70 \%$ confidence interval of each proportion.

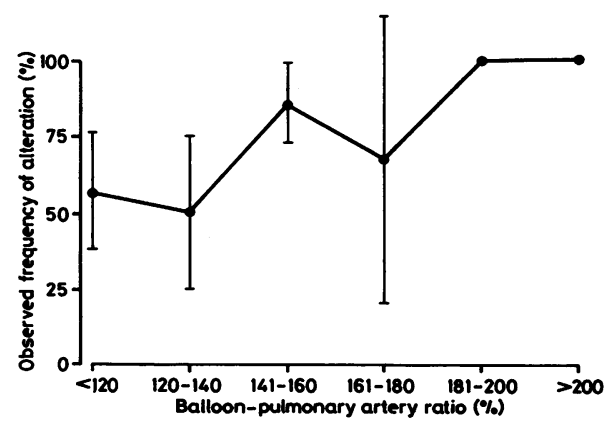

morphological change. Simple logistic regression analysis showed no relation between these two variables. None the less, there tended to be less damage with smaller balloon ratios (fig 4). The largest group with intact valves $(\mathbf{n}=3)$ had balloon/annulus ratios of $<120 \%$.

Eighteen patients $(67 \%)(70 \% \mathrm{CI}, 56 \%-$ $\mathbf{7 7 \%}$ ) required a transannular patch at the time of correction; and two (one after a limited transannular patch because of coronary artery anomalies) had an extracardiac conduit. There were three operative deaths. Two patients with classic tetralogy of Fallot died of low cardiac output, one of them with myocardial infarction resulting from a coronary artery injury. The third patient who died had Down's syndrome, tetralogy of Fallot, and a complete atrioventricular septal defect. He developed raised pulmonary vascular resistance and congestive heart failure after balloon dilatation of a stenosed Blalock shunt and the right ventricular outflow. The right ventricle proved inadequate to sustain the circulation postoperatively. Figures 2 and 3 show the heart from this patient.

Forty one $(36 \%)$ of the 113 patients in the "control" group who did not have balloon dilatation $(70 \%$ CI $31 \%-42 \%)$ had had a systemic pulmonary anastomosis before correction. A total of $26(63 \%)$ patients had one palliative operation, $14(34 \%)$ had two, and one $(2 \%)$ had three operations. Shunt operations were thus significantly more common in the non-dilatation group $\left(\chi^{2}=3 \cdot 12, \mathrm{p}=0.08\right)$, and fewer patients had surgical palliation when balloon dilatation had been performed. A transannular patch was required in $62(55 \%)$ of the group without prior balloon dilatation $(70 \% \mathrm{CI}, 50 \%-60 \%)$ and in $18(67 \%)$ of 27 of the dilatation group $(70 \% \mathrm{CI}, 55 \%-77 \%)\left(\chi^{2}\right.$ $=27, \mathrm{p}=0 \cdot 27$ ).

\section{Discussion}

Balloon dilatation of the pulmonary valve is an invasive, non-surgical technique ${ }^{1-3}$ used to relieve obstruction of the right ventricular outflow tract. ${ }^{4-6}$ The ideal balloon size, the number and pressure of inflations, and patient selection vary among different centres. Except for the report on the effect of balloon dilatation of the pulmonary annulus on newborn lambs from Ring and colleagues ${ }^{10}$ and mention of isolated surgical cases in series of pulmonary valve dilatations, ${ }^{78}$ there is little information available on the morphological consequences of the procedure on the right side of the heart. This, in part, attests to its relative safety and effectiveness, because few patients who have undergone dilatation of isolated pulmonary valve stenosis required later surgery.

Ring showed that balloon inflation severely damaged the right ventricular outflow tract in newborn lambs particularly when the balloon diameter was $>50 \%$ bigger than the pulmonary artery diameter. ${ }^{10}$ In animals killed 83 and 111 days after dilatation the damaged area was occupied by small patches of fibrosis. We did not find distinctive signs of this type of trauma in our patients at operation but in most patients with tetralogy of Fallot the endocardium in areas of turbulence is usually whitened and fibrotic. We have not examined enough patients to know whether fibrosis along the right ventricular outflow (which cannot be solely attributed to the dilatation scar) will predispose to ventricular arrhythmias-as was suggested by Ring $^{10}$ commenting on the clinicopathological study by Deanfield and colleagues. ${ }^{11}$ By using simple logistic regression analysis, we were unable to show any significant relation between the size of the balloon and occurrence of morphological changes (table 2), except for the general trend shown in fig 3. However, in one four month old patient, who has not yet come for correction (and therefore is not included in this report) sudden and severe hypotension and hypoxia after balloon dilatation required urgent systemicpulmonary artery anastomosis. After the chest was opened, blood was evacuated from a tense pericardium and we found disruption of the anterior right ventricular outflow tract with a large subadventitial haematoma extending across the annulus into the left pulmonary artery. Follow up catheterisation showed a small, round diverticulum protruding from the anterior aspect of the right ventricular outflow tract, confirming an extensive structural deformity.

The major changes in our series were confined to the valve leaflets; $20(74 \%)$ of patients $(70 \% \mathrm{CI}, 63 \%-83 \%)$ had one or more of the changes described, while $22(81 \%)(70 \% \mathrm{CI}$, 
$71 \%-89 \%$ ) were free of annular/pulmonary artery disruption. The frequency of the three categories of cusp alterations was very similar (table 1). It is striking that most of the morphological changes were found on the posterior leaflet and the posterior wall of the pulmonary trunk. We have not found an obvious explanation for this; but suggest that because this area has direct attachments to supporting structures, it would be less likely to distend under the balloon pressure and therefore would be more likely to tear or split. The anterior aspect probably is more elastic and compliant and would therefore stretch under pressure. Lock et al found multiple intimal tears in the lesions of lambs killed $<3$ days after dilatation of experimentally created branch pulmonary artery strictures. ${ }^{12}$ In some cases, these extended through all the arterial layers except the adventitia. In lambs killed 7 days after the procedure, all the tears were healed and the intima and media were intact; but the area of the old medial haemorrhage continued to show separation of fibres, with the blood replaced by smooth muscle cells. In view of the interval between dilatation and operation in our patients, we expected to find an avascular, fibrous area posteriorly at the site of previous intimal disruption. The long term importance, if any, of this alteration in the pulmonary outflow is uncertain.

The pattern of use of transannular patches was similar in patients who had operations for tetralogy of Fallot at our hospital during the same period as the group who had had balloon dilatation. Judged on the need for a transannular patch, we did not find that balloon dilatation resulted in appreciable growth of the pulmonary annulus. But because our study group contained few patients with angiograms both before and after dilatation we cannot be certain. It was also our impression that it was more difficult to achieve a competent pulmonary valve mechanism after balloon dilatation. Though the posterior cusp may be used to appose an anterior monocusp patch or some valve function can be achieved through a "two cusp plasty" technique, ${ }^{13}$ this was often thwarted by disruption of the posterior cusp. When we analysed the incidence of a systemic to pulmonary shunt in both groups, we included only patients in whom shunting was necessary after attempted palliation by balloon dilatation. Over a third $(36 \%)(70 \% \mathrm{CI}, 31 \%-$ $42 \%$ ) of the control patients had one or more shunt operations performed before correction compared with $19 \%(70 \% \mathrm{CI}, 11 \%-29 \%)$ in the study group which could be interpreted as showing that in $81 \%$ of patients $(70 \% \mathrm{CI}$, $71 \%-89 \%, \mathrm{n}=22$ ) a shunt was avoided, because satisfactory palliation was achieved by balloon dilatation. But the two groups were not strictly comparable in their underlying morphology, symptoms, or indications for palliation. A more rigorous, prospective randomised trial is necessary to compare accurately the role of percutaneous pulmonary balloon dilatation with surgical palliation for Fallot's tetralogy.

Given the present surgical thrust towards conservation of right ventricular and pulmonary valvar function, by means of a transatrial repair in tetralogy of Fallot, ${ }^{14}$ it is possible that palliation also should be directed towards conservation of the pulmonary valve mechanism. The long term effects of cusp damage in patients who did not require a transannular patch remain to be determined. However, accumulating evidence suggests that continuing pulmonary regurgitation may be detrimental to right ventricular function.

We found that balloon dilatation tended to split the posterior pulmonary valve leaflet or detach it from the hinge point, with or without a dehiscence in the posterior wall of the pulmonary artery. This may obviate the need for a systemic-pulmonary shunt, possibly at the expense of some anatomical damage and loss of valvar function at later correction. In view of these findings, we advise that the balloon size should be limited to $120 \%-140 \%$ of the diameter of the pulmonary annulus. From our present data, we cannot tell whether dilatation has any effect on the growth of the pulmonary arteries, ${ }^{15}$ but the procedure did not seem to alter the need for a transannular patch at the time of intracardiac repair.

We thank Dr Carlos Godinho for the pathological analysis: Dr Audrey Smith for her advice on the paper and assistance in documentation of the necropsy specimens, and Mr Ken Walters for his help in preparing the illustrations. Many of the patients reviewed in this study were at one time under the care of Dr J L reviewed in this study were at one time under the care of Dr J L
Wilkinson, Dr K Walsh, Dr J G C Wright, Dr S A Qureshi, Dr Wilkinson, Dr K Walsh, Dr J G C Wright, Dr S A Qureshi, Dr
RM Bini, or Professor D I Hamilton. SM was supported by the National Heart Research Fund, and $M J$ by the Cardiac Trust Fund.

1 Rubio-Almanez V, Cason RL, Soni J. Valvulotomias intracardiacas por medio de un cateter. Arch Inst Cardiol Mex 1953;23:183-92.

2 Semb BKH, Zjouneland S, Stake G, Aabyholm G. Balloon valvotomy of congenital pulmonary valve stenosis with bicuspid valve insufficiency. Cardiovasc Radiol 1979 2:239-41.

3 Kan JS, White RI Jr, Mitchell SE, Gudeman TJ. Percutaneous balloon valvuloplasty: a new method for treating congenital pulm

4 Fontes VF, Sousa JEMR, Esteves CA, Silva MVD, Cano MN, Maldonado G. Pulmonary valvoplasty-experience of 100 cases. Int $J$ Cardiol 1988;21:335-42.

5 Tynan M, Baker EJ, Rohmer J, et al. Percutaneous balloon ynan M, Baker EJ, Rohmer J, et al. Percutaneous bal
pulmonary valvuloplasty. Br Heart J 1985;53:520-4.

6 Rey C, Marache P, Matina D, Monly A. Valvuloplastie transluminale percutanee des stenoses pulmonaires: propos de 24 cas. Arch Mal Coeur 1985;78:703-10.

7 Lamb RK, Qureshi SA, Arnold R. Pulmonary artery tear following balloon valvuloplasty in Fallot's tetralogy. Int $J$ Cardiol 1987;15:347-9.

8 Lababidi Z, Wu J. Percutaneous balloon pulmonary valvuloplasty. Am J Cardiol 1983;52:560-2.

9 Qureshi SA, Kirk CR, Lamb RK, Amold R, Wilkinson JL. Balloon dilatation of the pulmonary valve in the first year of life in patients with tetralogy of Fallot: a preliminary study. Br Heart $J$ 1988;60:232-5.

10 Ring JC, Kulk TJ, Burke BA, Lock JE. Morphologic changes induced by dilatation of the pulmonary valve changes induced by dilatation of the pulmonary valve annulus with overlay balloon

11 Deanfield JE, Ho SY, Anderson RH, McKenna WJ, Allwork SP, Hallidie-Smith KA. Late sudden death afte repair of tetralogy of Fallot: a clinicopathologic study Circulation 1983;67:626-31.

12 Lock JE, Niemi T, Einzig S, Amplatz K, Burke B, Bass JL. Transvenous angioplasty of experimental branch pulmonary artery stenosis in newborn lambs. Circulation 1981;64:886-93.

13 Oku H, Shirotani H, Ohnishi H. Two-cusp plasty for the right ventricular outflow tract in complete repair of tetralogy of Fallot. Ann Thorac Surg 1988;45:97-8.

14 Pacifico AD, Sand ME, Bargeron LM Jr, Colvin EC. Transatrial-transpulmonary repair of tetralogy of Fallot. J Thorac Cardiovasc Surg 1987;93:919-24.

15 Parsons JM, Ladusans EJ, Qureshi SA. Growth of the pulmonary artery after neonatal balloon dilatation of the right ventricular outflow tract in an infant with the tetralogy of Fallot and atrioventricular septal defect. Br Heart $J$ 1989;62:65-8. 